\title{
Application of the large optimal node-driven model in tourism management
}

\author{
Luoyanchun \\ YIBIN VOCATIONAL AND TECHNICAL COLLEGE Sichuan yibin 644000 \\ E-mial:279679959@qq.com
}

\begin{abstract}
Nowadays, there are more and more factors affecting people's tourism demand, resulting in the increasing complexity in the judgment of people's tourist destinations at some fixed time. Due to the lack of necessary guidance mechanisms as well as relative fixed attribute weights of judgement factors, the traditional tourism management model can hardly manage the highly dynamic crowd effectively. In this paper, an optimized tourism management model of large optimal node-driven is put forward. Through extracting the relevant data of tourism passenger source, calculating the availability of tourism resources as well as performing the driven scheduling according to the status of tourism resource nodes everywhere, the tourism resources can be managed effectively with assurance. Experimental results show that through the use of the proposed model, the effect of management for tourism passenger source can be optimized significantly while the efficiency of the management can also be guaranteed.
\end{abstract}

Keywords- tourism passenger source; management model; node-driven

\section{INTRODUCTION}

With the continuous improvement of the people's living standards and the increasing development of the economic, the pursuit of the spiritual life is getting higher and higher ${ }^{[1]}$. What's more, the demand of people's travel has also showed the increasing trend in recent years ${ }^{[2]}$. The estimation of the flow of tourism passenger source is an important basis for tourism management in the tourism industry ${ }^{[3]}$. The reasonable scheduling and managing of the tourism resources according to the flow of tourism passenger source can provide adequate preparation for the travellers and guarantee the quality of tourism as well as the full use of tourism resources. Therefore, it is of very important economic significance to be engaged $\mathrm{in}^{[4]}$. The research on the issue of efficient management of tourism passenger source has already been carried out since the domestic tourism development was still in its infancy ${ }^{[5]}$. At this stage, the various of complex tourism data can be analyzed quickly and correctly on the computer, which provides powerful safeguard to the development of tourism management. Therefore, the research of relevant methods for tourism management comes to be the principal problem in tourism industry and attracts more and more attention from scholars. At this stage, the main tourist methods for the management of tourism resources are based on data mining algorithms. Based on the gray neural network algorithm, Liu et al proposed an estimation method for the flow of tourism passenger source. And based on the static forecasting model, Shang et al proposed another estimation method for the flow of tourism passenger source. Due to the wide range of applications, the tourism management has attract much of attention from many experts and has become the hot topic of study, and has a broad space for development.

\section{THE LARGE OPTIMAL NODE-DRIVEN MODEL FOR TOURISM MANAGEMENT}

\section{A. Construction of the management system for tourism passenger source data}

Through the use of the management method of principal component analysis, the relevant data on tourism passenger source can be collated, the characteristics can be extracted and the system of tourism passenger source data can also be established so as to provide accurate data basis for the estimation of the flow of tourism passenger source.

In the process of the management for the relevant data of tourism passenger source, the method of principal component analysis needs to be utilized to remove the redundant management data and select the principal components which eigenvalues are greater than 1 or weight coefficients are greater than 1 to be the data variables for the analysis of the flow of tourism passenger source. The steps are described as follows.

Through data analyzing by management data compression and dimensionality reduction as well as mapping process through matrix, the variance of all tourism management data components in low-dimensional space are made to reach the maximal value, and all the management data have strong independence. The steps are illuminated as follows.

(1) Set $y_{j} \in Y, j=1,2, \cdots, N$, then the following vectors with different dimensions can be obtained:

$$
z_{j k}=\frac{y_{j k}-\overline{y_{k}}}{t_{k}} \in Z
$$

Here, $\overline{y_{k}}$ is the average value of the tourism management vectors with different dimensions, while $t_{k}$ is the corresponding standard deviation.

(2) Use the following formula to calculate the covariance matrix: 


$$
T=\frac{1}{P}[Z-\overline{Z m})[Z-\overline{Z m}]^{U}
$$

$$
\begin{aligned}
& \text { Here, } \quad m=[1,1, \cdots, 1]_{m \times P} \quad, \quad \overline{z_{j}}=\frac{1}{P} \sum_{l=1}^{P} z_{j l} \\
& \bar{Z}=\left[\overline{z_{1}}, \bar{z}_{2}, \cdots, \overline{z_{N}}\right]^{U}
\end{aligned}
$$

(3) According to the characteristic equation on the flow of the tourism passenger source, $(\mu m-T) V=0$ to calculate the characteristic values.

(4) Use the following formula to calculate the principal component of the data on the flow of tourist passenger source:

$$
A_{k}=z_{j 1} V_{1 k}+z_{j 2} V_{2 k}+\cdots+z_{j P} V_{P} k, k=1,2, \cdots, q \leq P
$$

(5) Make the principal component contain a large number of effective management information to the greatest extent in the case of a smaller amount of data in accordance with the actual needs according to principle of the principal component selection.

\section{B. Calculation of the availability of tourism resources in management model}

Through the calculation of the availability of tourism resources, the tourism resources available to serve tourists can be collated and analyzed with a view to provide an accurate basis for the estimation of the flow of tourism passenger source. The availability of tourism resources is the reception capacity of the tourism resources, which must always be ready for tourists. According to the related theory on METRIC, the availability of tourism source can be denoted by the expectation of tourism resources. It is the expectation of the percentage of the tourism resources always available without the case of shortage of materials and any other cases to all the tourism resources, and can be calculated using the following equation:

$$
B=100 \prod_{j=1}^{J}\left[1-E B O_{j}\left(t_{j}\right) /\left(P A_{j}\right)\right]^{A_{j}}
$$

Here, $B$ is the availability of the tourism resources, $J$ is the number of all the tourism resources. $A_{j}$ is the probability of the tourism resources that serve the tourists from the jth terrain tract, while $\mathrm{P}$ is the quantity of the reception supplies ready for tourism passenger source. $E B O_{k}\left(u_{k}\right)$ is the expectation value of the reception capacity of the jth tourism resource named $t_{j}$. The following formula can be used to calculate the expectation value of the reception capacity of the tourism resources:
$E B O_{j}\left(t_{j}\right)=\sum_{y=t_{j}+1}^{\infty} y Q_{j}(y)-\sum_{y=t_{j}+1}^{\infty} t_{j} Q_{j}(y)=\sum_{y=t_{j}+1}^{\infty} y Q_{j}(y)-t_{j} \sum_{y=t_{j}+1}^{\infty} Q_{j}(y)$

Here, $Q_{j}(y)$ is the probability that the demanded quantity of tourist resources $\mathrm{j}$ is $\mathrm{y}$.

The availability of the tourism resources can be calculated using the following formula:

$$
\max \quad B=100 \prod_{j=1}^{J}\left[1-E B O_{j}\left(t_{j}\right) /\left(P A_{j}\right)\right] \quad \text { s.t. } \sum_{j=1}^{J} t_{j} \cdot d_{j} \leq D
$$

(6)

$$
\text { C. Construction of flow guiding model with driving }
$$
style

1) Principle

The reacted movements of single management node under the crowd attractant environment abide by the following assumptions:

(1) The running track of the crowd on the tourist route consists of a series of straight-line. The running curve is determined by three parameters, that is, speed, direction as well as movement time. Moreover, the speed is assumed to be constant.

(2) When the crowd determine to change the direction of motion, the probabilities of turning right and turning left are different, under the impact of certain driving force.

(3) Both the movement time of the crowd on the trajectory and the angle between the adjacent tracks meet a given probability distribution.

(4) The duration for the crowd on the driving trajectory meets the exponential distribution, and is gradually reduced with the increase of the number of iterations.

(5) The duration for the crowd on the driving trajectory and each angle between the adjacent tracks are independent of the direction and time parameters of the former trajectory.

2) Codes for constructing the model

Based on the assumptions mentioned above, the codes for the construction of the model abide by the following steps:

STEP1 Assume that the moving speed of the crowd is constant 1: $v=1$

STEP2 Calculate the moving time $\tau$ of the crowd on the new direction of tourism, and the value is determined by the following probability distribution:

$$
P(X=\tau)=\frac{1}{T} \exp \left(-\frac{\tau}{T}\right)
$$

The parameter $\mathrm{T}$ is determined by the following formula: 
$T= \begin{cases}T_{0}, & \text { for } \frac{f_{p r}}{l_{p r}} \geq 0 \\ T_{0}\left(1+b\left|\frac{f_{p r}}{l_{p r}}\right|\right), & \text { for } \frac{f_{p r}}{l_{p r}}<0\end{cases}$

STEP3 Calculate the new direction of movement of the crowd. The angle between the new direction and the original track obeys the following distributions respectively according to whether the new direction turned left or right:

$$
P(X=\alpha, v=\mu)=\frac{1}{\sqrt{2 \pi} \sigma} \exp \left[-\frac{(\alpha-v)^{2}}{2 \sigma^{2}}\right]
$$

$$
P(X=\alpha, v=-\mu)=\frac{1}{\sqrt{2 \pi} \sigma} \exp \left[-\frac{(\alpha-v)^{2}}{2 \sigma^{2}}\right]
$$

Here, the mathematical expectation $\mu=E(X)$ for variable $\mathrm{X}$ and the corresponding variance $\sigma=\operatorname{Var}(\mathrm{X}) 1 / 2$ are given according to the following equations: If $\mathrm{fpr} / \mathrm{lpr}<0$, then we have

$$
\begin{aligned}
& \mu=62^{\circ}(1-\cos \theta) \\
& \sigma=26^{\circ}(1-\cos \theta) \\
& \cos \theta=\exp \left(-\tau_{c} \tau_{p r}\right)
\end{aligned}
$$

Where, $\tau \mathrm{c}$ is the relevant time of the current movement trajectory of the crowd, while $\tau$ pr is the duration of the previous movement trajectory of the crowd. On the contrary, if fpr $/ \mathrm{lpr} \geq 0$, then we have $\mu=62^{\circ}, \sigma=26^{\circ}$.

STEP4 Calculate the new location of the crowd in the space with changeable driving force:

$$
x_{\text {new }}=x_{\text {old }}+n_{u} l
$$

Here, xnew is the new location of the crowd, xold is the last location of the crowd, nu is the normalized direction vector of the new track, 1 is the length of the new track.

Through the whole algorithm, T0, $\tau \mathrm{c}$ and $\mathrm{b}$ are the 3 parameters need to be preset, and they are related to the desired calculation accuracy $\varepsilon$ :

$$
\begin{aligned}
& T_{0}=\varepsilon^{0.30} 10^{-1.73} \\
& b=T_{0}\left(T_{0}^{-1.54} 10^{0.60}\right) \\
& \tau_{c}=\left(\frac{b}{T_{0}}\right)^{0.31} 10^{1.16}
\end{aligned}
$$

\section{ANALYSIS OF EXPERIMENTAL RESULTS}

\section{A. Data sources}

This paper takes the information on the flow of tourism passenger sources in the past five years as the basic data to perform the simulation experiments. Moreover, ten tourist landscape are selected as the subject investigated. The basic data can be described in the following table.

TABLE 1 TOURIST PASSENGER SOURCE DATA TABLE

\begin{tabular}{|c|c|c|c|c|c|}
\hline $\begin{array}{c}\text { Tourism } \\
\text { resources }\end{array}$ & $\begin{array}{c}\mathbf{2 0 0 7} \\
\mathbf{( 1 0 4} \\
\text { persons) }\end{array}$ & $\begin{array}{c}\mathbf{2 0 0 8} \\
\mathbf{( 1 0 4} \\
\text { persons) }\end{array}$ & $\begin{array}{c}\mathbf{2 0 0 9} \\
\mathbf{( 1 0 4} \\
\text { persons) }\end{array}$ & $\begin{array}{c}\mathbf{2 0 1 0} \\
\mathbf{( 1 0 4} \\
\text { persons) }\end{array}$ & $\begin{array}{c}\mathbf{2 0 1 1} \\
\mathbf{( 1 0 4} \\
\text { persons) }\end{array}$ \\
\hline 1 & 62 & 66 & 69 & 74 & 78 \\
\hline 2 & 21 & 23 & 24 & 27 & 31 \\
\hline 3 & 48 & 51 & 54 & 55 & 59 \\
\hline 4 & 30 & 32 & 33 & 35 & 37 \\
\hline 5 & 57 & 59 & 62 & 64 & 68 \\
\hline 6 & 68 & 71 & 73 & 74 & 78 \\
\hline 7 & 72 & 74 & 77 & 78 & 81 \\
\hline 8 & 85 & 87 & 88 & 91 & 93 \\
\hline 9 & 75 & 76 & 78 & 82 & 86 \\
\hline 10 & 93 & 95 & 97 & 98 & 102 \\
\hline
\end{tabular}

\section{B.Experimental results and analysis}

The reception capacity of the tourist flows and the amount of the corresponding tourist passenger sources can be estimated according to the relevant data about the flow of the tourism passenger sources mentioned above, and the results obtained can be described in the following table.

TABLE 2. MANAGEMENT MODEL OF TOURISM RESOURCE GUIDE EFFICIENCY

\begin{tabular}{|c|c|c|}
\hline Tourism resources & $\begin{array}{c}\text { Estimation of } \\
\text { availability } \mathbf{( \% )}\end{array}$ & $\begin{array}{c}\text { Estimation of the } \\
\text { amount of the } \\
\text { passenger sources } \\
\mathbf{( \% )}\end{array}$ \\
\hline 1 & 83 & 88 \\
\hline 2 & 75 & 86 \\
\hline 3 & 64 & 74 \\
\hline 4 & 85 & 78 \\
\hline 5 & 91 & 85 \\
\hline 6 & 64 & 58 \\
\hline 7 & 78 & 92 \\
\hline 8 & 75 & 89 \\
\hline 9 & 92 & 85 \\
\hline 10 & 81 & 71 \\
\hline
\end{tabular}

During the estimation of the flow of tourism passenger source, if the required tourism resource is less than the availability of the tourism resource, then the amount of the passenger source flowed to the tourism resources is to be the amount of required tourism resources. On the contrary, if the required tourism resource is greater than the availability of the tourism resource, then the amount of the passenger source flowed to the tourism resources is to be the amount of tourism resources available. The estimation of the flow of the tourism passenger sources in 2012 is performed using the traditional algorithm and the proposed algorithm respectively, and the results obtained are summarized and shown in the following table. 
TABLE 3 COMPARISON OF THE ESTIMATED RESULTS

\begin{tabular}{|c|c|c|c|}
\hline $\begin{array}{c}\text { Tourism } \\
\text { resources }\end{array}$ & $\begin{array}{c}\text { The actual } \\
\text { amount of } \\
\text { tourists (104 } \\
\text { persons) }\end{array}$ & $\begin{array}{c}\text { The amount of } \\
\text { tourists for } \\
\text { traditional } \\
\text { algorithm (104 } \\
\text { persons) }\end{array}$ & $\begin{array}{c}\text { The amount of } \\
\text { tourists for the } \\
\text { proposed } \\
\text { algorithm (104 } \\
\text { persons) }\end{array}$ \\
\hline 1 & 84 & 82 & 83 \\
\hline 2 & 35 & 31 & 34 \\
\hline 3 & 64 & 66 & 65 \\
\hline 4 & 41 & 38 & 40 \\
\hline 5 & 73 & 70 & 73 \\
\hline 6 & 82 & 78 & 83 \\
\hline 7 & 84 & 81 & 84 \\
\hline 8 & 95 & 92 & 95 \\
\hline 9 & 93 & 91 & 94 \\
\hline 10 & 106 & 103 & 105 \\
\hline
\end{tabular}

According to the experiment mentioned above, the accuracy of the estimation of the flow of the tourism passenger sources used with different management models can be obtained so as to provide the basis for decision-making in tourism industry. The trend of the accuracy of the estimations can be described with the following figure:

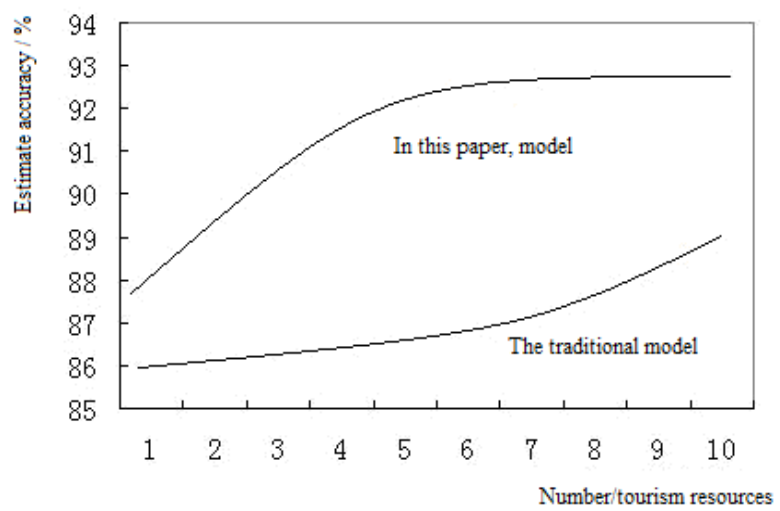

From figure 1, we can see that the accuracy of the estimation can be improved effectively using the proposed algorithm compared with traditional algorithm, resulting in satisfactory outcomes.

\section{CONCLUSIONS}

In this paper, an optimized tourism management model of large optimal node-driven is put forward. Through extracting the relevant data of tourism passenger source, calculating the availability of tourism resources as well as performing the driven scheduling according to the status of tourism resource nodes everywhere, the tourism resources can be managed effectively with assurance. Experimental results show that through the use of the proposed model, the effect of management for tourism passenger source can be optimized to a large extent while the efficiency of the management can also be guaranteed.

\section{REFERENCES}

[2] Liu Jing, Guan Wei. A Survey of Traffic Flow Forecasting Methods $[\mathrm{J}]$. Journal of Highway and Transportation Research and Development. 2004, vol. 21, no. 3, pp: 82-85.

[3] Shang Ning, Qin Minggui, Wang Yaqin et al. A BP Neural Network Method for Short-term Traffic Flow Forecasting on Crossroads[J]. Journal of Computer Applications and Software. 2006, vol. 23, no. 2, pp: 32-33

[4] Pei Yulong, Wang Xiaoning. Traffic impact forecast model based on the BP network[J]. Journal of Harbin Institute of Technology. 2004, vol. 36, no. 8, pp: 1034-1037.

[5] He Guoguang, Li Yu, Ma Shoufeng. Discussion on Short-term Traffic Flow Forecasting Methods Based on Mathematical Models[J]. Journal of Systems Engineering-theory \& Practice. 2000, vol 12, pp: 51-56.

[6] Fig.1 Trend of the accuracy of the estimation for different models 